\title{
Environmental protection behavior, innovation performance and enterprise performance --Take non-state-owned chemical industry as an example
}

\author{
Mingming Liu ${ }^{1, a}$, Hongjie Zhang ${ }^{2, b^{*}}$ \\ ${ }^{1}$ School of management, Dalian Polytechnic University, Ganjingzi District, Dalian, Liaoning, China \\ ${ }^{1}$ School of management, Dalian Polytechnic University, Ganjingzi District, Dalian, Liaoning, China
}

\begin{abstract}
As China attaches great importance to the construction of ecological civilization, the fiscal expenditure on environmental protection is increasing year by year, which needs to attract more social capital to participate in the construction of ecological civilization. As the main body of market economy, it is of great significance for enterprises to fulfill their environmental responsibilities. Especially when technological innovation has become the most important driving force for enterprise growth and national competition, the relationship between corporate environmental responsibility fulfillment and technological innovation has attracted more and more attention from all walks of life. Based on this, this paper uses 2015-2019 non-state-owned chemical industry listed companies as the research object to investigate whether environmental protection behavior affects enterprise performance and whether innovation performance plays a mediating role. It is found that there is a significant positive correlation between environmental protection behavior and enterprise performance, but innovation performance will not have a significant mediating effect on environmental protection behavior and enterprise performance in the short term.
\end{abstract}

\section{Introduction}

The report of the 19th National Congress of the Communist Party of China emphasizes that man and nature are a community of life, and human beings must respect, conform to and protect nature. Although China has made progress in the prevention and control of pollution, the pressure of environment on economy is still an urgent problem to be solved. The State Council, environmental protection departments and local governments have successively issued a series of environmental protection policies aiming at eliminating pollution, correcting market failure, improving resource allocation efficiency and promoting long-term sustainable economic development. These policies and regulations not only protect the ecological environment and effectively control the degree of pollution and ecological damage, but also have a certain degree of impact on China's economic environment and related enterprises, which is bound to affect the production activities of related enterprises, and then affect enterprise behavior and performance.

There are some research results on the control of enterprise emission by environmental protection policies in foreign countries. The research shows that environmental protection policies can effectively control the "three wastes" emission of relevant enterprises and reduce the environmental pollution caused by them. Some studies believe that environmental protection behavior will limit the development of pollution intensive enterprises and reduce their competitiveness. However,

doubleming618@163.com

*Corresponding author: 15776563099@163.com appropriate and appropriate environmental regulation can accelerate the technological innovation of enterprises, enhance the competitiveness of enterprises through "first mover advantage" and "innovation compensation", and achieve a win-win situation of environmental and economic benefits. Domestic research in environmental protection and other related fields started a little later than abroad, but it has developed rapidly, and has achieved rich results so far. Zhang (2016) took China's listed manufacturing enterprises as samples, established an environmental responsibility index system instead of selecting specific variables to measure the value of environmental responsibility, and then found that there was a significant positive correlation between environmental protection behavior and enterprise performance through theoretical research. There are some researches on environmental protection, innovation performance and enterprise performance at home and abroad, but there is a lack of corresponding empirical analysis. Based on the existing literature, this paper makes an empirical analysis by using 2015-2019 non-state-owned chemical industry listed companies as the research object.

The possible marginal contributions of this paper are as follows: first, in terms of research methods, this paper focuses on the empirical analysis of the relationship between corporate environmental protection behavior and corporate performance, which further enriches the literature in the field of environmental protection. Secondly, this paper expands the research content, analyzes and tests the effect of environmental protection 
behavior of listed enterprises in non-state-owned chemical industry on enterprise performance, and introduces innovation performance as an mediating variables, which is helpful for a deeper understanding of the economic impact of environmental protection responsibility fulfillment. Thirdly, most of the previous studies focused on financial listed companies. This paper takes the non-state-owned chemical industry as the main research object, which enriches the literature on the impact of environmental protection on enterprises.

\section{Theoretical basis and research hypothesis}

\subsection{The impact of environmental protection behavior on Enterprise Performance}

According to the resource-based theory, the green practice of enterprises is helpful to improve the innovation ability and organizational ability, realize the purpose of energy conservation and emission reduction, and improve production efficiency. Parkk and other scholars collected financial data and environmental responsibility data released by financial companies from different countries as research samples to study the impact of corporate environmental responsibility on financial performance. They found that corporate environmental responsibility has a negative impact on ROA in the short term, but with the growth of years, the impact of corporate environmental responsibility on ROA gradually changed from negative to positive. Similarly, Zhang and others take the listed companies of heavy pollution industries in Shenzhen and Shanghai stock markets from 2010 to 2017 as research samples, and find that corporate environmental responsibility has a positive impact on lag financial performance. Christopf (2017) found that there is a U-shaped nonlinear relationship between corporate environmental responsibility and financial performance. Nowadays, the environmental protection laws and regulations are becoming more and more strict, the cost of environmental violations will be greater and greater, and the benefits brought by ignoring environmental protection will be reduced. That is to say, the implementation of environmental protection behavior can also avoid administrative punishment for environmental non-compliance, and can indirectly improve financial performance by reducing the cost of environmental violations. With the increasing intensity of environmental protection supervision, only by actively implementing environmental protection behavior can enterprises win the support of the government, the public and investors, so as to further enhance the core competitiveness of enterprises. Based on the above analysis, this paper puts forward research hypothesis 1:

H1: The implementation of environmental protection will promote the performance of enterprises

\subsection{The impact of environmental protection behavior on enterprise innovation performance}

With the continuous deepening of the concept of green sustainable development, the technological innovation of enterprises has gradually developed to green innovation in recent years. On the one hand, it is driven by the international standards of environmental protection for enterprise products, on the other hand, it is also caused by the improvement of environmental awareness and social responsibility awareness of investors and consumers. Yang(2016) and other studies found that corporate social responsibility can attract more stakeholders to supervise the management, which can reduce the agency cost of enterprises, promote higher R\&D investment, and ultimately promote innovation performance. Especially in recent years, with the continuous improvement of China's environmental pressure and the continuous enhancement of social awareness of environmental protection and environmental responsibility, enterprises will pay more attention to the upgrading and improvement of technology and process in the process of actively fulfilling their environmental responsibility. Li (2011) have studied the impact of environmental regulation law on enterprise innovation investment, and found that the order control environmental regulation law has a significant impact on enterprise innovation investment, while the market-based incentive environmental regulation law has no significant impact. Based on the above analysis, this paper proposes hypothesis 2 :

$\mathrm{H} 2$ : Better implementation of environmental protection behavior will improve the innovation performance of enterprises

\subsection{The mediating effect of enterprise innovation performance on environmental protection behavior and enterprise performance}

Pandit (2011) research shows that the increase of patent output can effectively improve the financial performance of enterprises; and through innovation, human resources, organizational culture and other invisible resources that can form the competitive advantage of enterprises, corporate social responsibility can be linked with financial performance. Porter hypothesis holds that the environmental protection investment of enterprises is not a "pure" expenditure, but a resource that can enhance the competitiveness and financial performance of enterprises. Environmental protection behavior can improve enterprise innovation performance, and then improve financial performance, such as environmental protection technology research and development to improve the enterprise's innovation ability; environmental protection equipment, technology investment to achieve enterprise energy saving and emission reduction, reduce costs; the introduction of environmental protection products is conducive to increase sales, so as to improve production efficiency and enterprise's comprehensive competitiveness.

In view of the attention paid to environmental protection by all sectors of society in China in recent 
years, enterprises are bound to effectively integrate the performance of environmental protection behaviors into their business activities and technological innovation process, so as to produce more socially responsible products. In this way, it can not only get more support from stakeholders, but also meet the demands of the market and consumers for "green products". With the strengthening of environmental responsibility and the improvement of technological advantages of enterprise innovation output, it will promote the future financial performance of enterprises. Based on the above analysis, this paper propose hypotheses 3 :

H3: Enterprise innovation performance plays a mediating role in the relationship between environmental protection behavior and enterprise performance

\section{Sample selection and data analysis}

\subsection{Samples and data}

This paper selects 2015-2019 listed companies in China's non-state-owned chemical industry as the initial research sample. According to the research practice, the initial sample data are screened as follows: (1) the samples of ST and delisted companies are removed; (2) the enterprises with serious missing key variables and data are removed. (3) In order to prevent some company data from being abnormal, all continuous variables are Winsorize by $1 \%$. Finally, 160 sample observations were obtained. The financial data and environmental protection data of the listed companies used in this paper are from CSMAR.

\subsection{Modeling and variable definition}

\subsubsection{Model establishment}

Based on the method of mediating effect test, this paper uses the mediating effect test model to test whether environmental protection behavior affects the performance of listed enterprises in non-state-owned chemical industry. The specific model settings are as follows:

$$
\begin{aligned}
& R O A_{\mathrm{i}, \mathrm{t}}=\alpha_{0}+\alpha_{1} E N_{i, t}+\text { Controls }_{i, t}+\varepsilon \\
& R D_{\mathrm{i}, \mathrm{t}}=\beta_{0}+\beta_{1} E N_{i, t}+\text { Controls }_{i, t}+\varepsilon \\
& R O A_{\mathrm{i}, \mathrm{t}}=\gamma_{0}+\gamma_{1} E N_{i, t}+\gamma_{2} R D_{\mathrm{i}, \mathrm{t}}+\text { Controls }_{i, t}+\varepsilon
\end{aligned}
$$

Among them, $\mathrm{ROA}_{\mathrm{i}, \mathrm{t}}$ is the performance of enterprise $i$ in the $t$-th year; $\mathrm{EN}_{\mathrm{i}, \mathrm{t}}$ is the environmental protection behavior of enterprise $i$ in the $t$-th year; $R D_{i, t}$ is the annual innovation performance of enterprise; controls is other control variables; $\varepsilon$ is the random interference term, representing the unpredictable random error caused by subjective and objective reasons.

\subsubsection{Variable definition}

Explained variable: This paper uses the return on assets (ROA) as the basic financial index to measure the financial performance of the company. Return on assets refers to the ratio of the company's net profit to the average total assets of the year. It is an index to measure the profitability of an enterprise. The larger the index value is, the higher the financial performance level of an enterprise is.

Explanatory variables: foreign studies mainly use CEP index or specific pollution emission data released by TRI database to measure the environmental performance of companies. However, there is no similar environmental performance evaluation system in China, and there is no specific pollutant emission database. Therefore, this paper uses the evaluation method of Xue for reference, evaluates the environmental protection behavior of enterprises by using the ratio of environmental protection investment to main business income, and marks it with EN. The higher the EN value is, the higher the implementation level of environmental protection behavior is. The calculation formula is as follows:

$\mathrm{EN}=$ total investment for environmental protection / total operating income

Intermediary variable: This paper uses the ratio of annual RD expenses to business income to measure the annual innovation performance.

Control variables: in order to eliminate the influence of other unknown factors as far as possible, referring to the previous research results and the characteristics of this study, we select the enterprise age, enterprise size, financial leverage, equity concentration, operational efficiency as the control variables.

\section{Empirical results and analysis}

\subsection{Descriptive statistics}

Table1 shows the descriptive statistical results of 160 observations from 2015 to 2019. It can be seen from table1 that the range of enterprise performance (ROA), innovation performance (RD), environmental protection behavior (EN) and other variables is large, which indicates that there are obvious differences among the relevant variables among enterprises.

Table1 Descriptive Statistics

\begin{tabular}{c|c|c|c|c}
\hline Variable & Mean & Std. Dev. & Min & Max \\
\hline ROA & .066 & .042 & .005 & .204 \\
\hline EN & .035 & .063 & .01 & .513 \\
\hline RD & 3.073 & 1.551 & .02 & 6.59 \\
\hline age & 2.901 & 0.223 & 2.079 & 3.367 \\
\hline size & 7.573 & 1.067 & 4.779 & 9.986 \\
\hline lev & 1.243 & .575 & .826 & 5.317 \\
\hline most & 33.569 & 14.304 & 9.98 & 73.19 \\
\hline cat & 1.501 & .734 & .492 & 5.141 \\
\hline
\end{tabular}

\subsection{Regression analysis}

Table2 shows the empirical test of the intermediary model. From the data results in column (1) of the regression results, it can be seen that the environmental protection behavior in the model (1) has passed the 
regression test. The explanatory variable $\mathrm{EN}$ is significantly correlated with the explained variable ROA at the level of $1 \%$, and the coefficient is positive, indicating that the environmental protection behavior of enterprises is positively correlated with the enterprise performance, thus hypothesis 1 is verified. From the data of regression result (2), we can see that environmental protection behavior is positively correlated with innovation performance in model (2), but it is not significant. It shows that environmental protection behavior has no significant impact on the innovation performance of enterprises in non-state-owned chemical industry. The possible reasons include the increase of the proportion of environmental protection funds invested, On the one hand, it will limit the available funds for enterprise innovation investment, on the other hand, it will promote enterprise investment in innovation behavior, so as to reduce environmental protection investment and enhance enterprise competitiveness through innovation strive for strength and obtain greater benefits. Hypothesis 2 has not been verified, that is, in the non-state-owned chemical industry, innovation performance does not play a significant intermediary role between environmental protection behavior and enterprise performance. Through the regression results (3), we can see that innovation performance has a significant positive correlation with enterprise performance.

Table2 Regression model of mediating effect

\begin{tabular}{|c|c|c|c|}
\hline \multirow{2}{*}{ Variable } & $(1)$ & $(2)$ & (3) \\
\hline & ROA & $\mathrm{RD}$ & ROA \\
\hline EN & $\begin{array}{c}0.210 * * * \\
(4.66)\end{array}$ & $\begin{array}{l}1.517 \\
(0.84)\end{array}$ & $\begin{array}{c}0.202 * * * \\
(4.56)\end{array}$ \\
\hline $\mathrm{RD}$ & & & $\begin{array}{c}0.005 * * * \\
(2.64) \\
\end{array}$ \\
\hline age & $\begin{array}{l}-0.015 \\
(-1.15)\end{array}$ & $\begin{array}{l}0.217 \\
(0.42)\end{array}$ & $\begin{array}{l}-0.016 \\
(-1.26)\end{array}$ \\
\hline size & $\begin{array}{c}-0.007 * * \\
(-2.57)\end{array}$ & $\begin{array}{c}-0.350 * * * \\
(-3.05)\end{array}$ & $\begin{array}{c}-0.006^{*} \\
(-1.92)\end{array}$ \\
\hline lev & $\begin{array}{c}-0.028 * * * \\
(-5.78)\end{array}$ & $\begin{array}{c}-0.653 * * * \\
(-3.29)\end{array}$ & $\begin{array}{c}-0.025 * * * \\
(-5.01)\end{array}$ \\
\hline most & $\begin{array}{c}0.000 * \\
(1.71)\end{array}$ & $\begin{array}{l}0.008 \\
(0.96)\end{array}$ & $\begin{array}{l}0.000 \\
(1.53)\end{array}$ \\
\hline cat & $\begin{array}{c}0.009 * * \\
(2.12)\end{array}$ & $\begin{array}{c}-0.402 * * \\
(-2.44)\end{array}$ & $\begin{array}{c}0.011 * * * \\
(2.63)\end{array}$ \\
\hline Constant & $\begin{array}{c}0.168 * * * \\
\quad(4.18)\end{array}$ & $\begin{array}{c}6.195^{* * * *} \\
(3.83)\end{array}$ & $\begin{array}{c}0.136^{* * *} \\
(3.29)\end{array}$ \\
\hline R-squared & 0.335 & 0.202 & 0.365 \\
\hline
\end{tabular}

\section{Research conclusion}

This paper takes the listed companies in China's non-state-owned chemical industry from 2015 to 2019 as the initial research sample, uses the mediating effect test model to study the impact of environmental protection behavior on enterprise performance through innovation performance, and puts forward research hypotheses. It is found that enterprises can improve enterprise performance through the implementation of environmental protection behavior, but innovation performance does not play a significant mediating role, The implementation of environmental protection has no significant impact on innovation performance. The conclusions of this paper enrich the research literature on the economic consequences of environmental protection behavior in non-state-owned chemical industry. There are still some deficiencies in this paper: the impact of environmental protection behavior on innovation performance has not been accurately concluded; the research is only limited to the short-term effect of environmental protection behavior, but not the long-term effect, and does not take into account the lag of the impact of environmental protection behavior on innovation performance and enterprise performance .If we use longer time sample data for research, we can further improve the conclusion of this paper.

\section{References}

1. C. Trump, T. Guenther. BSE, 26, 7 (2017)

2. K.A. Cook, A.M. Romi, D. Sánchez, J.M. Sánchez. JBFA, 46, 44 (2019)

3. S. Pandit, C.E. Wasley, T. Zach. JAAF, 26, 24 (2011)

4. L. Zhang,. Economic Research Guide, 08, 2 (2016)

5. B. Yang, C. Lin. Journal of Yunnan University of Finance and Economics, 32, 4 (2016)

6. Y.N. Li, F. Ye. Studies in Science of Science, 29, 12 (2011) 